\title{
SUPPORT FOR THE CONTINUATION OF FEMALE GENITAL MUTILATION AMONG ADOLESCENTS IN JIMMA ZONE, SOUTHWEST ETHIOPIA
}

\author{
Abebe G.Mariam ${ }^{1}$, Assefa Hailemariam ${ }^{2}$, Tefera Belachew ${ }^{1}$, Kifle W.Michael ${ }^{3}$, David \\ Lindstrom ${ }^{4}$
}

ABSTRACT

BACKGROUND: Female genital mutilation/cutting is a harmful practice which has effect on female's wellbeing. However, the practice has continued to prevail in many cultures. Research on the social determinants of the practice and its continuation are scarce. The objective of this study was to assess whether attitude towards the continuation of female genital mutilation is predicted by gender role perception among adolescents in Jimma zone.

METHODS: This study used data collected in the first round of Jimma Longitudinal Family Survey of Youth. A total of 2084 adolescents were identified from 3700 households and one adolescent were interviewed from each household using structured questionnaire. Data on the socio-demographic characteristics, religiosity, access to electronic media, perception of gender role, attitude towards continuation of Female circumcision was collected. Descriptive and multivariate statistical techniques were used to analyze the data using SPSS for windows version 16.0. Statically tests were performed at the level of significance of $5 \%$.

RESULTS: Of the 2084 adolescents, 1146 (55.0\%) were aged 12 -14 years, 1025 (49.2\%) females and 749 (35.9\%) from rural areas. The majority, 1289 (61.9\%) were Muslims and 1351 (64.8\%) Oromo. Five hundred seventy three (28.1\%) of the male youth did not agree to the importance of marrying a circumcised girl. However, 149 (13.8\%) and 258 (12.7\%) agreed that it is very important and important, to marry a circumcised girl, respectively. On multivariate logistic regression analysis, perception of gender role, sex, place of residence, highest education in the household and religion remained to be important predictors of attitude towards the continuation of female genital mutilation after adjustment for age and ethnicity. Adolescents who had low gender role perception were 1.4 times more likely to have a positive attitude towards the continuation of the female genital mutilation (OR: 95\%CI, 1.41: 1.02-1.94). Female adolescents were 36\% less likely to support $(P<0.01)$ the continuation of FGM compared to their male counter parts (OR: 0.64; 95\%CI: 0.49, 0.83). Compared to urban youth, those who live in semi urban and rural areas were 1.46 and 1.52 times more likely to have a positive attitude towards the continuation of the FGM practice, respectively $(P<0.05)$. Similarly the Probability of having positive attitude towards the continuation of the FGM practice decreased steadily as the highest educational level in the household increased.

CONCLUSION: One-fifth of the youth support the continuation of the practice. Low gender roles perception, being from the rural areas, household's lower level of education and being Muslim were strong predictors of the attitude towards the continuation of female genital mutilation. Improving perception of adolescents towards gender roles through effective behavior change communication, and involving religious leaders in the campaign against the practice of female genital mutilation is recommended as a useful strategy to ban the practice.

KEY WORDS: Youth, female genital mutilation, Gender role, Jimma

${ }^{1}$ Population \& Family Health Department, Jimma University, ${ }^{2}$ Institute of Population Studies, Addis Ababa University, ${ }^{3}$ Department of Epidemiology, Jimma University ${ }^{4}$ Population Studies Center, Brown University, USA

Corresponding author:

Professor Abebe G/Mariam, Jimma University, PO. Box 378, Jimma, Ethiopia 


\section{INTRODUCTION}

Among the various forms of gender-based violence, female genital mutilation/cutting (FGM) - sometimes known as female circumcision - is a particularly dangerous practice that frequently has serious negative consequences on the health and wellbeing of women and girls (1-3). FGM is a collective name that refers to those procedures, conducted for cultural or other reasons that involve the partial or total removal of the female genitalia and/or cause injury to it (4). FGM is performed for reasons that include; sexual (to control or reduce female sexuality), sociological (as an initiation for girls into womanhood, social integration and the maintenance of social cohesion), hygiene and aesthetic reasons (due to a belief that the female genitalia are dirty and unsightly), health (in the belief that it enhances fertility and child survival) and for religious reasonsdue to the mistaken belief that it is a religious requirement $(4,5)$. It is practiced in a few Middle Eastern and Asian countries with the highest prevalence in Africa $(5,6)$.

Eighty percent or more of the women undergo FGM in Egypt, Sudan, Ethiopia, Djibouti, Mali and Guinea, $(6-8)$. Though it is considered by human rights and researchers to be an extremely dangerous practice FGM practice is widespread $(8,9)$.

Ethiopia has taken steps towards the abolition of the practice and created a supportive policy environment in which various local and international organizations can work towards the elimination of the practice. In spite of this, the practice remains widespread. According to data from the 2005 EDHS, three out of every four women had undergone FGM. Thirty eight percent of women with a daughter reported having at least one of their daughters circumcised, and that about a third of all women support the continuation of the practice. FGM is practiced in all regions in Ethiopia, but the magnitude varies considerably from region to region ranging from less than $30 \%$ in Gambella and Tigray to over $90 \%$ in Afar, Dire Dawa and Somali $(16,17)$.

In the absence of any perceived medical necessity, it subjects females to irreversible lifelong health risks and life-threatening consequences. The consequences could be acute like severe bleeding infection, fistula, urine retention, stress, reproductive tract infection, pelvic inflammatory diseases, chronic urinary tract obstruction/bladder stones and shock or chronic including damage to the urethra or anus and disruption of normal sexual function, difficulty in menstruation/ painful menstruation; difficult delivery/obstructed labor, cysts, excessive growth of scar tissue, painful sexual intercourse, increased susceptibility to HIV/AIDS and hepatitis and other blood-borne diseases and urinary incontinence $(5,9$ 15).

While there are ample data on the prevalence of FGM, there is paucity of information on the gender role perception on the attitude towards the continuation of female genital mutilation. This study assessed whether attitude towards the continuation of female genital mutilation is predicted by gender role perception among adolescents in Jimma zone

\section{SUBJECTS AND METHODS}

Jimma Zone is one of the 18 zones in Oromia Region of Ethiopia located in South Western Ethiopia. It is inhabited primarily by the Oromo Ethnic group and has diverse cultural backgrounds. Administratively, it is divided into 18 districts and city administration. It has a population of 2.2 million in the year 2006 of which $50.3 \%$ were males and $49.7 \%$ were females (18). As estimated from the projected 1994 CSA data approximately $20 \%$ of the adolescent people are between the ages of $13-17$ years (17). The majority $(94.3 \%)$ of the population lives in rural areas. Islam was the predominant religion followed by Christianity. The main source of livelihood is agriculture for more than $90 \%$ of the population.

For the this study, the data from the first round of the Jimma Longitudinal Family Survey of youth (JLFSY), conducted by a team of researchers from Jimma and Brown Universities between September 2005 and March 2006 was used.

Eighteen Kebeles, six from Jimma City, Serbo, Yebu and Sheky Towns and three rural kebeles each surrounding the above towns from Kersa, Mana and Dedo districts were included in the study. Out of the 5,795 households in the study area, 3,700 were randomly selected and then 2,100 adolescents fulfilling the inclusion criteria were enrolled in the study. Up to two adolescents ages 13-17 years were interviewed from each sampled household. In households where there were more than one adolescent male or female, one adolescent of each sex was randomly selected and interviewed. In the cases where there was no adolescent in the household, the next randomly selected household was visited. This included household heads and spouses of the head aged 13-17, children of the head residing in the household and any other adolescent identified by the household head or spouse of the head as a member of the household. A total of 2,084 adolescents aged 13-17 years were interviewed. Adolescents who were resident in the household, but who were not considered members of the household, such as visitors, maids, renters, or those who were 
not physically and mentally capable of completing the interview (for example, deaf or mentally disabled) were excluded.

Structured questionnaires were first prepared in English, translated into Oromiffa and Amharic languages, and back translated into English to check for consistency in the translation. Before the conduct of data collection, pre-test of the questionnaire and training of supervisors and interviewers were done. Males interviewed male adolescents and females interviewed female adolescents.

Information on demographic and socio-economic characteristics, religiosity, access to mass media (radio, TV and newspapers), perceptions of gender roles, and attitudes towards continuation of FGM were collected. Religiosity was further measured using responses to the following questions: How often do you go to church/mosque on religious days? How often do you fast on religious fasting days? How often do you attend religious institutions outside home? How often do you pray? How important is religion to you? Moreover, information on ethnicity, place of residence (City, small town and rural area) and household earnings/income per week were collected. Attitude towards gender role perceptions was measured using an index computed from affirmative responses to each of the following statements: a woman should always listen to her husband; normally a man should not have to do housework; marriage by abduction is acceptable; a husband should have a final say in all major family matters; a woman should not marry a man of her choice; a woman can do nothing if her husband wants to have a mistress; a woman cannot be a Woreda administrator; a wife cannot control all monthly income of the family; a wife should not be able to initiate a divorce if she wants one; it is not acceptable for females to buy condoms; and it is not acceptable if woman teaches safe sex in a community. Scores ranging from 1-3 were assigned (low, medium and higher gender role perception).

The data were entered twice for consistency and analyzed using SPSS for Windows version 12.0. Descriptive statistics were used to summarize basic adolescent characteristics, while logistic regression was used to adjust effect of the independent variables on the dependent variable. The strength of association was measured using OR at 95\% confidence intervals. P-values below 0.05 were considered statistically significant.

The study was approved by the Ethical Review Committee of Jimma University and the Institutional Review Board of Brown University. Consent was obtained from the household head and the adolescent, before the interviews began. The respondents were guaranteed that their responses would remain confidential and were told to stop the interview at any time if they wish so.

\section{RESULTS}

Data were collected from 2084 adolescents from sampled 2100 making a response rate of $99.2 \%$. Their age ranged from 13 to 17 years with mean 14.8 $(\mathrm{SD}= \pm 1.3)$ years. The majority $1146(55.0 \%)$ were in the age group of 15-17 years. There were 1059 males and 1035 females giving a sex ratio of 1.02 . Seven hundred forty six $(35.8 \%)$ were from Jimma City, while $589(28.3 \%)$ and $749(35.9 \%)$ were from the three towns and the 9 rural kebeles, respectively. Oromo accounted for 1351 (64.4\%), 1289 (61.9\%) were Muslims and 1966 (94.3\%) had some formal education (Table 1). 
Table 1. Socio-demographic characteristics of the study subjects, Jimma Zone, March 2006

\begin{tabular}{lcc}
\hline Variables(N=2084) & Frequency & Percent \\
\hline Age & & \\
$12-14$ & 938 & 45.0 \\
$15-17$ & 1146 & 55.0 \\
Sex & & \\
Male & 1059 & 50.8 \\
Female & 1025 & 49.2 \\
Place of residence & & \\
City & 746 & 35.8 \\
small town & 589 & 28.3 \\
rural area & 749 & 35.9 \\
Ethnicity & & \\
Oromo & 1351 & 64.8 \\
Amhara & 213 & 10.2 \\
Kefa & 81 & 3.9 \\
Daworo & 176 & 8.4 \\
Gurage & 125 & 6.0 \\
Yem & 46 & 2.2 \\
Tigre & 19 & .9 \\
Wolaita & 34 & 1.6 \\
Other & 39 & 1.8 \\
Religion & & \\
Muslim & 1289 & 61.9 \\
orthodox & 685 & 32.9 \\
protestant & 104 & 5.0 \\
Other (Catholic, Traditional) & 6 & 0.2 \\
Education & & \\
Illiterate & 118 & 5.7 \\
Lower primary $(1-4)$ & 672 & 52.4 \\
Upper Primary(5-8) & 1093 & \\
Secondary \& above $(\geq 9)$ & 201 & \\
\hline
\end{tabular}

Significantly high proportion of Orthodox Christians $602(89.5 \%)$ and Muslims 933(73.4\%) were against the practice. There was a statistically significant association between religion and attitude towards the continuation $(p<0.05)$. Those who went to Church/mosque on religious days all of the time 166 $(17.8 \%)$, fasted on religious fasting days all of the time $204(19.4 \%)$, those who practiced religious instructions outside home 203 (23.8\%) and those who reported that religion is important to them 370 $(20.2 \%)$ agree that FGM should continue (Table 2$)$.

Lower proportion $(14.8 \%)$ of youth who had access to functional electronic media such as radio, television and recorder supported the continuation of the practice compared to those who did not have (33.5\%), (Fig 1).

Large proportion $(90 \%)$ of youth who had more egalitarian perception towards gender roles had negative attitude towards the continuation of the FGM practice compared to those with a medium and low perception of gender role accounting for $80 \%$ and $60 \%$, respectively, (Fig. 2).

Large proportion $573(28.1 \%)$ of the male youth did not agree to the importance of marrying a circumcised girls. However, 149 (13.8\%) and 258 $(12.7 \%)$ agreed that it is very important and important, to marry a circumcised girl, respectively (Fig. 3). 
Table 2. Attitude towards the continuation of FGM by religion \& religiosity, Jimma Zone, March 2006

\begin{tabular}{|c|c|c|c|c|}
\hline \multirow[t]{2}{*}{ Religiosity variables } & \multicolumn{2}{|c|}{ FGM Should Continue } & \multirow[t]{2}{*}{ Total } & \multirow[t]{2}{*}{ PV } \\
\hline & Disagree & Agree & & \\
\hline \multicolumn{5}{|l|}{ Religion $(\mathrm{N}=2053)$} \\
\hline Muslim & $933(73.4)$ & $338(26.6)$ & $1271(100.0)$ & \\
\hline Orthodox & $602(89.5)$ & $71(10.5)$ & $673(100.0)$ & \\
\hline Others* & $101(92.7)$ & $8(7.3)$ & $109(100.0)$ & 0.000 \\
\hline \multicolumn{5}{|l|}{ How often do you go to Church/mosque on } \\
\hline All the time & $254(72.8)$ & $95(27.2)$ & $349(100.0)$ & \\
\hline Most of the time & $447(80.3)$ & $110(19.7)$ & $557(100.0)$ & \\
\hline Some times & $93(78.2)$ & $26(21.8)$ & $119(100.0)$ & \\
\hline Rarely & $71(78.9)$ & $19(21.1)$ & $90(100.0)$ & 0.007 \\
\hline \multicolumn{5}{|l|}{ Never } \\
\hline \multicolumn{5}{|l|}{ How often do you fast on religious fasting } \\
\hline All of the time & $200(73.3)$ & $73(26.7)$ & $1054(100.0)$ & \\
\hline Most of the time & $374(79.6)$ & $96(20.4)$ & $273(100.0)$ & \\
\hline Sometimes & $77(74.8)$ & $26(25.2)$ & $470(100.0)$ & \\
\hline Rarely & $121(88.3)$ & $16(11.7)$ & $103(100.0)$ & \\
\hline Never & & & $137(100.0)$ & 0.004 \\
\hline \multicolumn{5}{|l|}{ How often do you pray? $(\mathrm{N}=2053)$} \\
\hline Daily & $824(80.4)$ & 201(19.6) & $1025(100.0)$ & \\
\hline At least once a week & $328(79.6)$ & $84(20.4)$ & $412(100.0)$ & \\
\hline Rarely & $390(78.9)$ & $104(21.1)$ & 494(100.0) & \\
\hline Never & $94(77.0)$ & $28(23.0)$ & $122(100.0)$ & 0.8 \\
\hline \multicolumn{5}{|l|}{$\begin{array}{l}\text { Do you practice religious instruction } \\
\text { outside home }(n=2053) \text { ? }\end{array}$} \\
\hline No & $649(76.2)$ & 203(23.8) & $852(100.0)$ & \\
\hline Yes & $987(82.2)$ & $214(17.8)$ & $1201(100.0)$ & 0.001 \\
\hline \multicolumn{5}{|l|}{ How important is religion to you $(\mathrm{N}=2053)$} \\
\hline Very important & $1463(79.8)$ & $370(20.2)$ & $1833(100.0)$ & \\
\hline Important & $132(76.3)$ & $41(23.7)$ & $173(100.0)$ & \\
\hline Somewhat important & $41(87.2)$ & $6(12.8)$ & $47(100.0)$ & 0.235 \\
\hline
\end{tabular}

*Protestant, Catholic and traditional religions; Note: 31 to 49 cases out of the total were not considered in the analysis for their response were I don't know

On bivariate analysis variables including age, sex, highest level of education in the household, respondents' education level, place of residence, religion and perception of gender role were significantly associated with attitude towards the continuation of female genital mutilation $(\mathrm{P}<0.005)$. Respondents of female sex, age 15 - 17 years, living in household with highest level of education of 9 years and above, urban residents, followers of protestant religion, and those who had a higher perception of gender role had negative attitude towards the continuation of FGM. However, on multivariate logistic regression analysis, perception of gender role, sex, place of residence, highest education in the household, and religion remained to be important predictors of attitude towards the continuation of FGM after adjusting for age and ethnicity. Adolescents who had low gender role perception were 1.4 time more likely to have a positive attitude $(\mathrm{P}=0.038)$ towards the continuation of the FGM (OR: 1.41; 95\%CI: 1.02, 1.94) (Table 3).

Female adolescents were $36 \%$ less likely to support $(\mathrm{P}=0.001)$ the continuation of FGM compared to their male counter parts (OR: 0.64; 95\%CI: $0.49,0.83)$. The relationship between attitude towards the continuation of FGM and place 
of residence showed a pattern such that compared to urban youth the probability of supporting the continuation FGM increased as one moves from urban area through semi urban $(\mathrm{P}=0.042)$ to rural areas $(\mathrm{P}=0.038)$. Compared to urban youth, those who live in semi urban and rural areas were 1.46 and 1.52 times more likely to have a positive attitude towards the continuation of the FGM practice, respectively. Similarly the Probability of having positive attitude towards the continuation of the FGM practice decreased steadily as the highest educational level in the household increased (Figure 4).

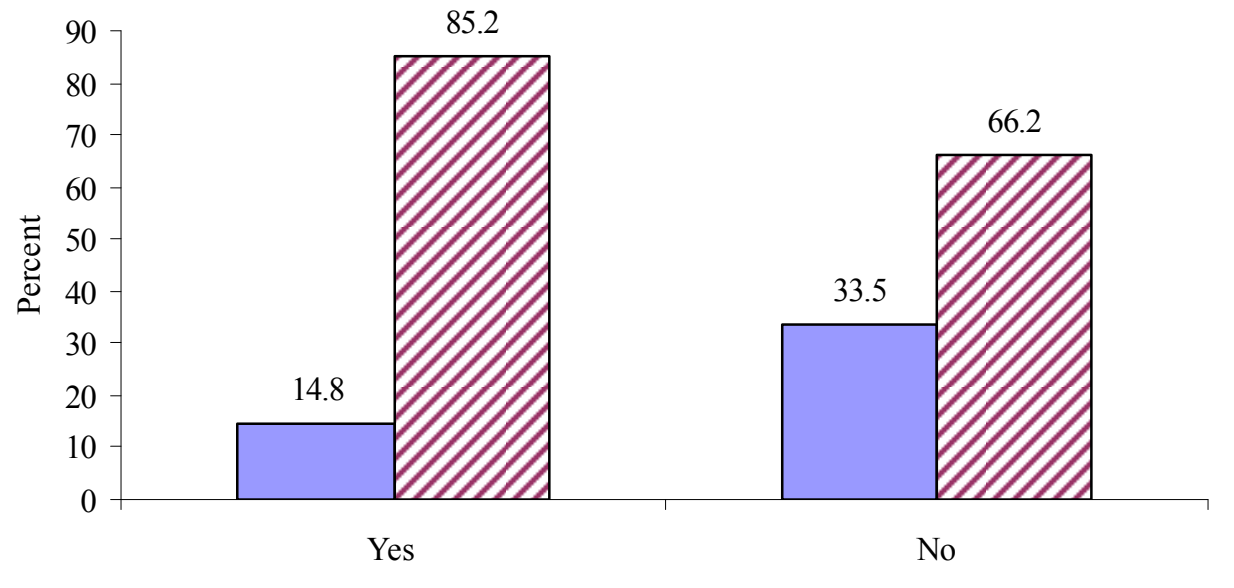

Acess to eclectronic media $\square$ Agree

D Disagree

Figure 1. Attitude towards the continuation of FGM by access to electronic media, Jimma 2006.

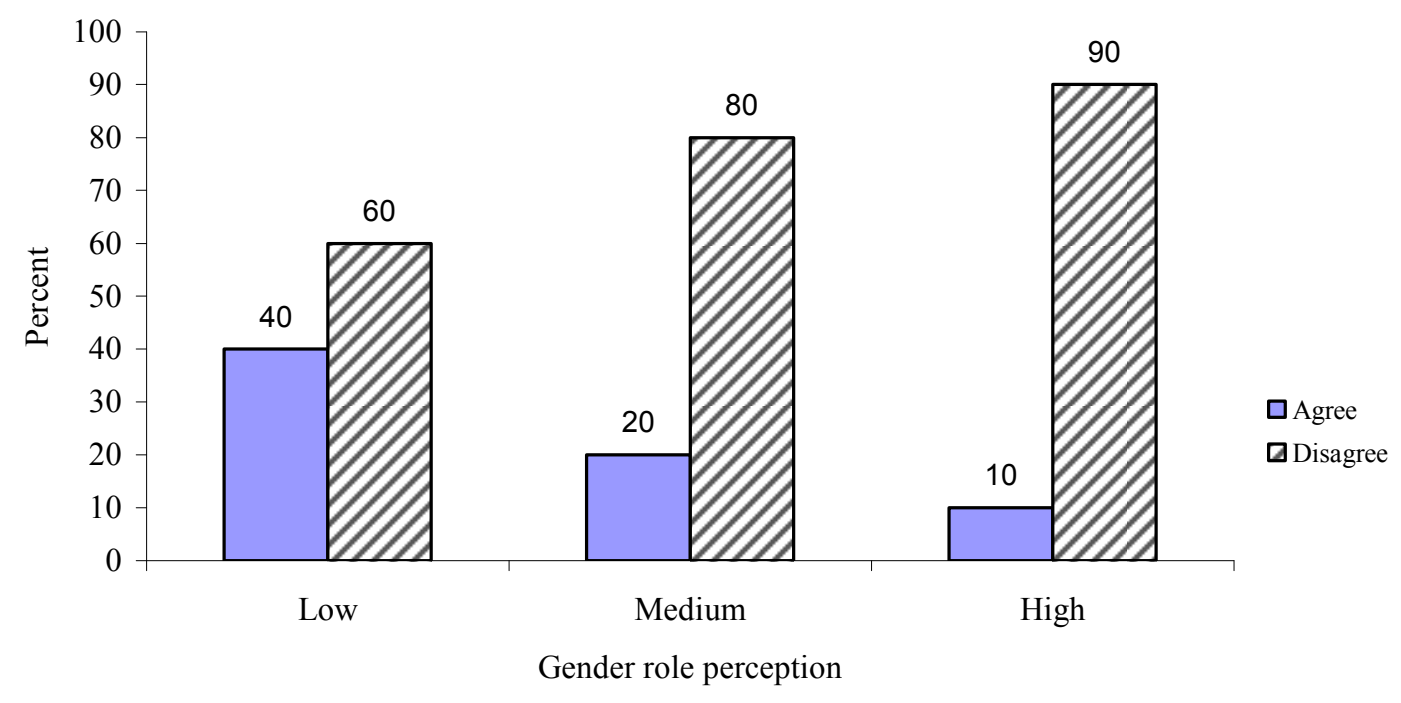

Figure 2. Attitude towards the Continuation of FGM by Gender Role Perception, Jimma, 2006(P<0.05). 
Table3. Coefficients and adjusted odds ratios from logistic regression model predicting the probability of adolescents supporting the continuation of the practice of FGM. Jimma Zone, March 2006

\begin{tabular}{|c|c|c|c|c|c|c|}
\hline \multirow[t]{2}{*}{ Predictors } & & \multirow[b]{2}{*}{$\mathrm{B}$} & \multirow[b]{2}{*}{$\mathrm{P}$ value } & \multirow{2}{*}{$\begin{array}{l}\text { Adjusted } \\
\text { OR }\end{array}$} & \multicolumn{2}{|c|}{ 95.0\% C.I. EXP(B) } \\
\hline & & & & & Lower & Upper \\
\hline \multicolumn{7}{|l|}{ Sex } \\
\hline Male & & & & 1 & & \\
\hline Female & & -.451 & 0.001 & 0.637 & 0.489 & 0.830 \\
\hline \multicolumn{7}{|l|}{ Age } \\
\hline$<15$ & & & & 1 & & \\
\hline $15-17$ & & .040 & 0.452 & 1.041 & 0.937 & 1.156 \\
\hline \multicolumn{7}{|l|}{ Place of residence } \\
\hline City & & & & 1 & & \\
\hline Small town & & .377 & 0.042 & 1.458 & 1.014 & 2.094 \\
\hline Rural & & .415 & 0.038 & 1.515 & 1.023 & 2.244 \\
\hline \multicolumn{7}{|l|}{ Educational status } \\
\hline Illiterate & & & & 1 & & \\
\hline Lower primary(1-4) & & -.604 & 0.032 & 0.547 & 0.315 & 0.949 \\
\hline Higher Primary (5-8) & & -1.388 & 0.000 & 0.250 & 0.141 & 0.441 \\
\hline Secondary \& above $(\geq 9)$ & & -1.772 & 0.000 & 0.170 & 0.075 & 0.387 \\
\hline \multicolumn{7}{|l|}{ Ethnicity } \\
\hline Oromo & & & & 1 & & \\
\hline Amhara & & -.203 & 0.529 & 0.816 & 0.433 & 1.538 \\
\hline Kefa & & -.011 & 0.980 & 0.989 & 0.438 & 2.235 \\
\hline Dawero & & .229 & 0.441 & 1.258 & 0.702 & 2.254 \\
\hline Gurage & & .399 & 0.178 & 1.490 & 0.834 & 2.661 \\
\hline Others(Yem, Tigre, Wolayta) & & -.050 & 0.878 & 0.951 & 0.500 & 1.808 \\
\hline Access to electronic Media & & & & 1 & & \\
\hline Yes & & -.167 & 0.234 & 0.847 & 0.643 & 1.114 \\
\hline \multicolumn{7}{|l|}{ No } \\
\hline \multicolumn{7}{|l|}{ Gender role perception } \\
\hline \multicolumn{7}{|l|}{ High } \\
\hline Medium & & -.483 & 0.010 & 0.617 & 0.428 & 0.890 \\
\hline Low & & .340 & 0.038 & 1.405 & 1.019 & 1.939 \\
\hline \multicolumn{7}{|l|}{ Muslim } \\
\hline Orthodox & & & & 1 & & \\
\hline Others(Protestant, & $\&$ & -.472 & 0.028 & 0.624 & 0.409 & 0.950 \\
\hline Traditional) & & -.855 & 0.049 & 0.425 & 0.182 & 0.996 \\
\hline Constant & & -2.047 & 0.013 & 0.129 & & \\
\hline
\end{tabular}




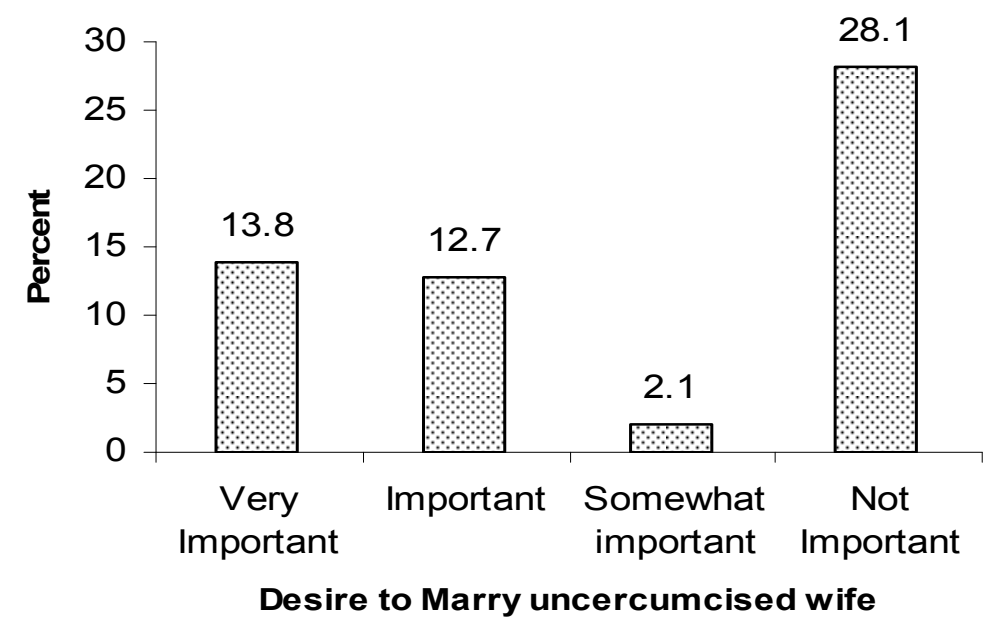

Figure 3:- Desire to Marry a Circumcised Wife among Male Adolescents in Jimma Zone Southwest Ethiopia, Jimma 2006.

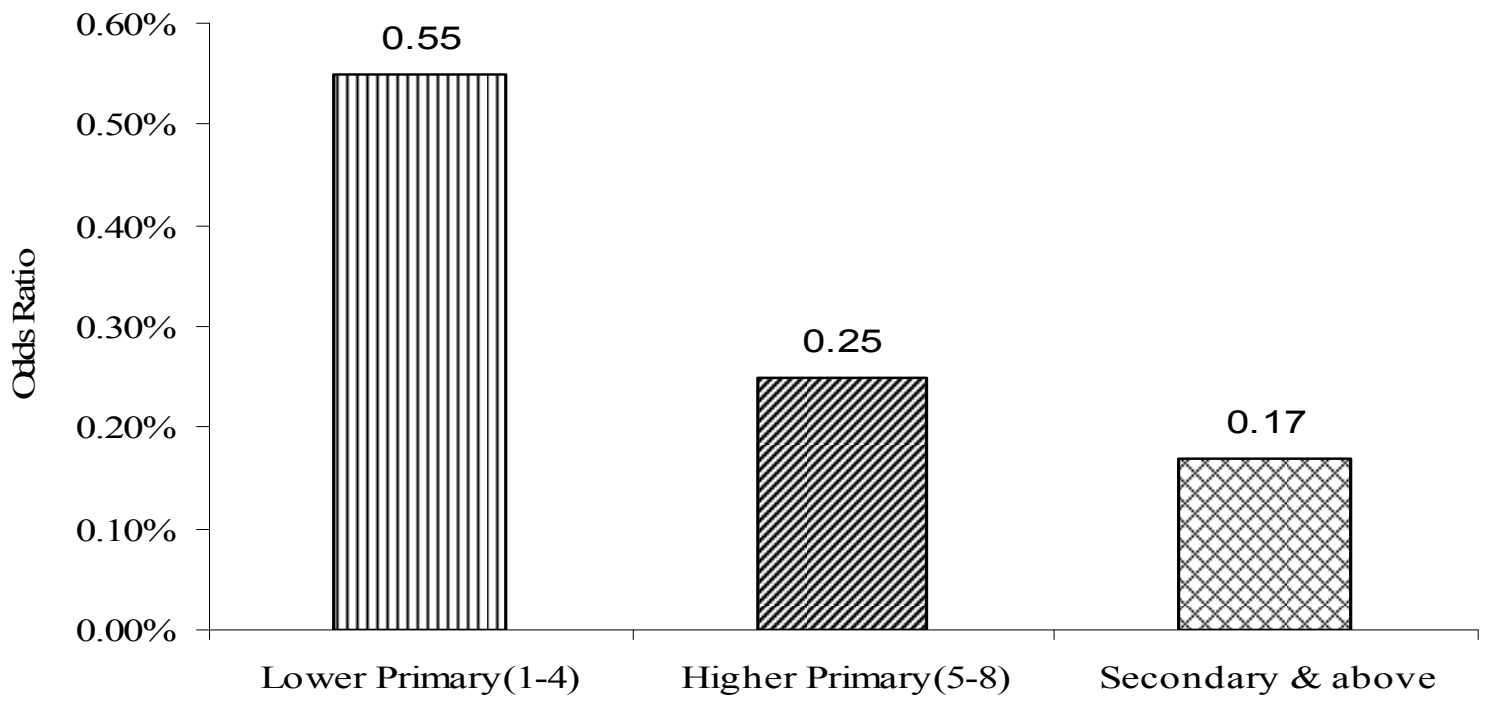

Highest Education in the Hous ehold

Figure4. Odds Ratio of supporting the continuation of FGM Practice by level of household education

\section{DISCUSSION}

Despite the overall lack of change in the percentage of girls who undergo circumcision, changes in attitude seem to be occurring in some countries. For instance in Eritrea, women and men younger that 25 years are more likely to believe that circumcision should not continue than those older than 40 years, while there is a little change in this regard in Sudan(31). In this study, education, religion, ethnicity, place of residence, gender roles and access to media are identified as influential factor for eliminating the practice of FGM. Education appears to be the most important factor affecting attitude of youth towards continuation FGM. With increasing highest level of education, the proportion of youth 
who support the continuation of the practice decreased. This might be due to the fact that when education increases awareness about the consequences of female circumcision increases leading to a decrease in the practice of female circumcision.

Place of residence is another variable that is associated with the levels of support for the discontinuation of FGM. Levels of support variations based on residence are probably deep rooted in such factors as the area's ethnic composition, dominance of religious affiliation, and level of urbanization (10). In this study, adolescents living in cities were less supportive of the continuation of the practice compared to those living in small towns or rural areas. Adolescents living in rural areas have shown significantly higher levels of support for the continuation of FGM than their urban (Jimma) counter-parts. This may be somewhat understated, where prevalence levels are generally higher in urban areas and may obscure the urban-rural differences in prevalence as reported else where (19).

There are no identified religious justifications or origins for the maintenance of FGM. However, Muslims, Christians, Animists and non-believers in a range of cultures practice it as a religious requirement $(20,21)$. The relationship between the practice and religion is not consistent. In the present study, high proportion of adolescents belonging to both Orthodox and Protestant Christianity were found to be supporting the discontinuation of the practice. However, Muslims appeared more supportive compared to followers of other religions (Orthodox or Protestant Christians) in supporting the continuation of the practice. Studies in six African countries also show that Muslims are more likely to practice FGM than Christians $(22,23)$. Contrary to our findings, there seems to be no significant religious difference in Niger, Nigeria and Tanzania (5). Access to media was another variable which showed effect on youth attitude against FGM. More than three-quarters $(76.9 \%)$ of the youth living in households with functioning Radio, TV or Tape recorder were against the practice. This finding is consistent with findings in other studies $(25,26)$.

In this study, adolescents whose gender roles was high or those who were empowered did not support the continuation of the practice suggesting that empowering females /improving their socioeconomic status will make a significant contribution towards preventing FGM. The rationale behind the cultural significance of the practice of FGM mostly revolves around social definition of feminism and attitude towards women sexuality. The common feature is that the social conditioning of women's acceptance of FGM is within the social definition of womanhood, and identity. This led women to defend the practice, although many societies acknowledge the dampening effect of genital mutilation on women sexual drive (26).

One third of male adolescent in this study reported that they prefer a circumcised woman to be their future spouse. Similar findings were also reported in other studies $(27,28)$. Despite the fact that FGM affects the health of girls and women, it is still desired by some men and women to be practiced because of its cultural significance. The commonest reasons given to justify the practice include: social background - in Somalia for instance, a girl who has not been infibulated is ridiculed and often driven out of her community and she has little chance of marriage (21). A study conducted in six regions of Ethiopia revealed that the desire to maintain the traditional gender relationship, that is, the belief in some communities that uncircumcised girl will become disobedient, uncontrollable, powerful, untamed, and, generally, ill mannered as a factor that contributed for the continuation of the practice (29).

A WHO working group study report also showed that $84 \%$ of their sample stated that tradition was the main reason for continuing the practice. As noted, FGM is a prerequisite for marriages in many areas. The low status of women and their economic dependence on men for livelihood could be a major determinant of their willingness to undergo the procedure. Despite its dreadful complications (28), in some African countries, uncut women are considered illegitimate for marriage and ineligible to inherit money or cattle (30).

In conclusion, the practice of female circumcision is widespread, with three in four women age 15-49 circumcised in Ethiopia and more than two-third of women aged 15-49 approve the continuation of FGM in Ethiopia (17). The findings of the JLFSY also shows that about one-third of the youth support the continuation of the practice. Youth whose gender roles are high or those who are empowered do not support the continuation of the practice suggesting that empowering females /improving their socioeconomic status is likely to make a significant contribution towards banning the practice. As education is an important variable in exposing the youth to the health and psychosocial consequences of FGM, encouraging the youth beyond primary education is also likely to make a significant contribution to put an end to the practice. Moreover, as access to media, especially, having functional radio or $\mathrm{TV}$ in the household was found to be strongly associated with the practice, improving access to electronic mass media is likely to make a significant contribution to abolish the practice. Designing a culturally sensitive, appropriate and 
acceptable radio messages that address the negative effects of the practice and at the same time demonstrating a lack of religious support for the practice be considered as an important intervention strategy for banning the practice.

\section{ACKNOWLEDGEMENTS}

We are highly grateful to the David and Lucile Packard Foundation for funding the study. We also appreciate the cooperation of adolescents in giving information. We thank other research team members: Prof. Craig Hadley, Prof. Dennis Hogan, Mr. Fasil Tesemma and Prof.Challi Jira. We also thank all the data collectors

\section{REFERENCES}

1. Karungary K. Female genital mutilation: A reproductive health concern. Population Rep 1995; 23:4.

2. Mawad NM, Hassanein OM. Female circumcision: Three years' experience of common complications in patients treated in Khartoum teaching hospitals. J Obstet Gynaecol 1994; 14:40-43.

3. United Nations. United Nations Economic and Social Council, Concluding Observations of the Committee on Economic Social and Cultural Rights 1998: Nigeria 13/05/98.

4. World Health Organization. WHO Fact Sheet No. 241, Female Genital mutilation. 2000.WHO, Geneva

5. Hedayat, K. M and Pirradeh Roya. Issues in Islamic Biomedical Ethics: a Primer for the Pediatrician 2006; 108(4):965-71.

6. Hanly GM, Objeda VJ.. Epidermal inclusion cysts of the clitoris as a complication of female circumcision and Pharonic Infibulations. Cent Afr J Med 1995; 41:22-24.

7. Morison L, Scherf C, Ekpo G, Paine K, West B, Coleman $\mathrm{R}$, et al.. The long-term reproductive health consequences of female genital cutting in rural Gambia: a community based survey. Trop Med Int. Health 2001; 6: 643-53.

8. Toubia N. Female circumcision as a public health issue. N Engl. J Med 1994; 331: 712-6.

9. International Planned Parenthood Federation (IPPF). The Link between Female Genital Mutilation and HIV Transmission. IPPF 2007.

10. Isa AR, Shuib R, Othman MS. The practice of female circumcision among Muslims in Kelantan, Malaysia. Reproductive Health Matters 1999; 7: 137 - 44.

11. Brady, M. 'Female Genital Mutilation and the Risk of HIV Transmission' in Journal of Aids, Patient Care and STDs, 1999; 13 (12): 709-716.
12. Kun, K. 'Female genital mutilation: the potential for increased risk of HIV infection' in International Journal of Gynecology \& Obstetrics, 1997; 59 (2: 153-155.

13. Caldwell, J.C., I.O. Orubuloye, P. Caldwell, "Male and Female Excision in Africa from a Regional to a Specific Nigerian Examination," Social Science and Medicine, 1997; 44(8): 11811193.

14. National Committee on Traditional Practices in Ethiopia Addis-Ababa Ethiopia (NCTPE); female genital mutilation, Ethiopia, Addis Ababa, 1999: 32-33.

15. Dorkenoo E. Cutting the rose: female genital mutilation: the practice and its prevention. London: Minority Rights Publications: 1994(13).

16. Population Council. Female circumcision in Indonesia: extent, implications and possible interventions to uphold women's health rights. Jakarta, Indonesia: 2003; Population Council.

17. Central Statistical Agency (Ethiopia) and ORC Macro. Ethiopia Demographic and Health Survey 2005. Addis Ababa, Ethiopia and Calverton, Maryland, USA. 2006. Central Statistical Agency and ORC Macro.

18. Federal Democratic Republic of Ethiopia, Population Census Commission (2008). Summary and Statistical Report of the 2007 Population and Housing Census: Population Size by Age and Sex.

19. Department of Statistics and Institute for Resource Development/Macro International. Sudan Demographic and Health Survey 1989/1990. Columbia, MD: Department of Statistics and Institute for Resource Development/Macro International.

20. Toubia Nahid. "The social and political implications of female circumcision: The case of Sudan" In: Fernea. 1985. Women and the Family in the Middle East.

21. Warsame, M. Medical and social aspect of female circumcision in Somalia, in female circumcision strategies to bring about change, published by Italian Association of women in development and Somali women's demographic organization: 1997; 97.

22. World Health Organization (WHO). 'Female Genital Mutilation and Obstetric Outcome: A Collaborative Prospective Study in six African Countries' Lancet 2006t: 367:1835-41.

23. Dareer A. Epidemiology of Female Circumcision in the Sudan. Trop Doc 1983; 13: 41-5. 
24. Odiyinrin O.M. Akitoye CO. Oyediran MA. A study on female circumcision in Nigeria. J. Med.; 1989; 8(3): 183-192.

25. UNICEF. Female Genital cutting: a situation exploration (2005). Available at www.unicef.org/protection/index_genitalmutilati on.html)

26. World Health Organization (WHO). Female Genital Mutilation - Programs to date: What works and what does not - A review, 1999.

27. Manressa, Kim and Anna Soler Port. Spnifex Press and Female Genital Mutilation: Answers to hard questions 1999. Available at www.women@spnifexpress.com.au

28. Barstow, G., D. Female Genital Mutilation: The Penultimate Gender Abuse. Child Abuse \& Neglect. 1999; 23(5): 501-510.
29. Birhan Research and Development Consultancy. Formative Research for designing an entertainment-education radio serial drama to address women's concerns and harmful traditional practices with particular emphasis on FGM: Findings of survey, 2008.

30. World Health Organization WHO Technical Working Group. Female Genital Mutilation. 1996; Geneva, WHO.

31. E.-H. Kheir, S. Kumar and A.R. Cross, "Female Circumcision: Attitudes and Practices in Sudan," in Proceedings of the Demographic and Health Surveys World Conference, Washington, D.C., 1991, Vol. 3, Columbia, Md., USA, 1991, pp. 1697-1717; and A. El Dareer, Woman, Why Do You Weep? Zed Books, London, 1982. 